\title{
High-intensity focused ultrasound liver destruction through the gastric wall under endoscopic ultra- sound control: first experience in living pigs
}

High-intensity focused ultrasound (HIFU) was first developed to ablate prostatic tissue [1]. The ultrasound beam is focused at the focal point of the transducer and the energy concentration produces tissue necrosis [2]. HIFU has also been used to ablate metastases on the surface of the liver either surgically or via the transcutaneous approach $[3,4]$. However, beam reflection on gastric gas has produced necrosis of the interposed abdominal wall [5]. An endoscopic device is potentially valuable in treating tumors localized near to the gastric lumen without the difficulties of gas interposition. We developed an endoscopic ultrasound (EUS) HIFU device. We report the first experience of the use of HIFU to treat lesions completely endoscopically under EUS control.

We designed a miniaturized HIFU transducer with a 40-mm focal point, a working frequency of $3.8 \mathrm{MHz}$, and an acoustic power of $35 \mathrm{~W}$. We adapted it to fit onto an Olympus linear echoendoscope ( $\bullet$ Fig. 1). To test this new device, a living pig model was chosen because of its similarity to the human digestive anatomy.

The procedure was performed in two pigs that had been given general anesthetics. In each pig, the stomach was initially filled with degassed water. The prototype was then placed on a guide wire in the gastric lumen and focused onto the left lobe of the liver under EUS control (๑ Fig. 2). We applied 10 consecutive shots each of 10 seconds and with an effective acoustic power of $35 \mathrm{~W}$. This was repeated five times moving the scope $2 \mathrm{~cm}$ between each group of shots. No bleeding or other complications occurred during the procedures.

The pigs were sacrificed immediately after the procedures. Examination showed that we had achieved complete necrosis of the liver at the five sites with lesions in the

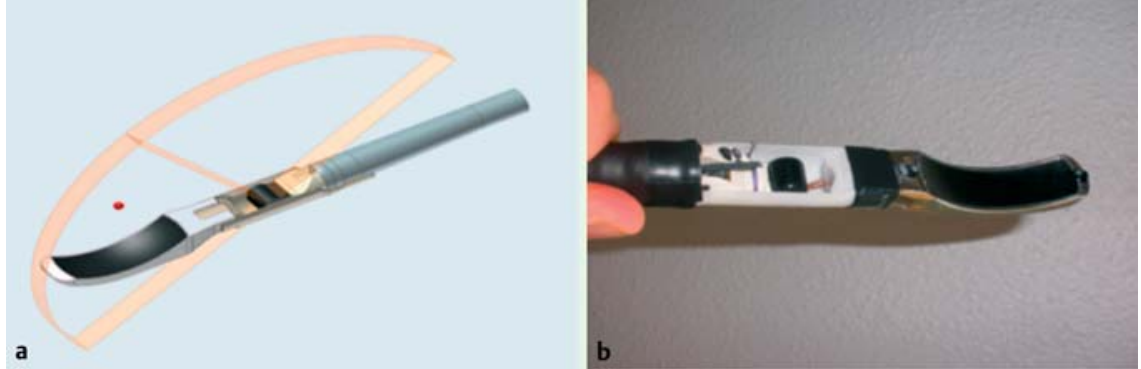

Fig. 1 The endoscopic ultrasound (EUS) high-intensity focused ultrasound (HIFU) device: a a threedimensional (3-D) representation of the prototype; $\mathbf{b}$ a photograph of the final prototype.

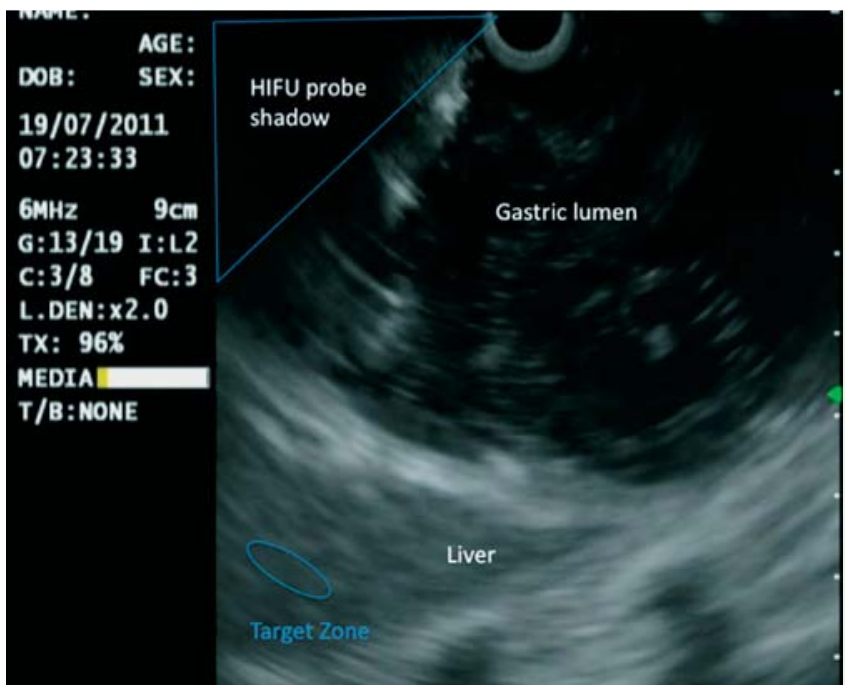

Fig. 2 Endoscopic ultrasound (EUS) image highlighting the target zone within the liver.

liver $10 \mathrm{~mm}$ in length and $8 \mathrm{~mm}$ in depth ( Fig.3). Only one of the five sites showed evidence of gastric mucosal erythema with whitening of the external gastric wall but with no evidence of perforation or muscle wall damage. The target zone appeared hypoechoic on the EUS endoscopy.

We report for the first time the ability to make HIFU lesions on the liver with a completely endoscopic procedure under EUS control with no immediate adverse effects. Other possible targets that could be treated in this way include pancreatic tumors or nodes.

This work was supported by a grant from the Agence Nationale de la Recherche (ANR) through the Programme Blanc 2008.

Endoscopy_UCTN_Code_TTT_1AS_2AG

Competing interests: None 

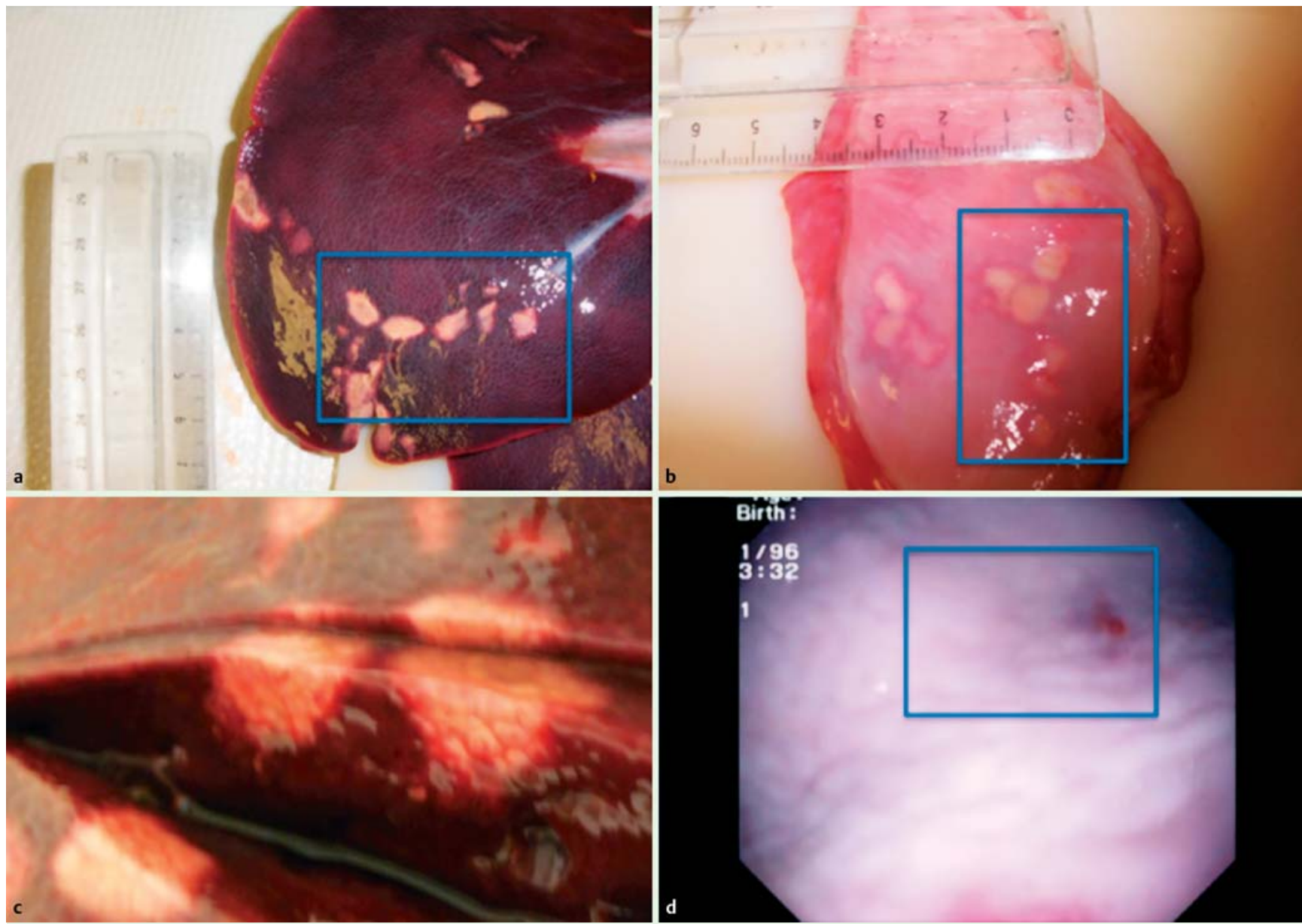

Fig. 3 Appearances at necropsy following endoscopic ultrasound (EUS)-guided high-intensity focused ultrasound (HIFU) treatment showing: a the liver with five pale areas (within blue box) consistent with the treated zones; $\mathbf{b}$ the cut surface of the liver indicating the depth of the lesions; $\mathbf{c}$ the surface of the gastric wall with an area of external whitening. $\mathbf{d}$ Endoscopic appearance of the gastric mucosa following HIFU treatment. Other lesions correspond to the probe test at the beginning of the experiments.

M. Pioche ${ }^{1,2}$, C. Lafon ${ }^{1}$, E. Constanciel ${ }^{1}$, A. Vignot ${ }^{1}$, A. Birer ${ }^{1}$, R. Gincul ${ }^{2}$, V. Lépilliez ${ }^{2}$, F. Prat ${ }^{1,3}$, S. Roman ${ }^{1,2}$, J.-Y. Chapelon'2, J. C. Saurin², T. Ponchon ${ }^{1,2}$

${ }^{1}$ Inserm U1032, LabTau, Lyon, France

2 Department of Gastroenterology, Edouard Herriot Hospital, Hospices Civils de Lyon, Lyon, France

${ }^{3}$ Department of Gastroenterology, Cochin Hospital, AP-HP, Paris, France

\section{References}

1 Thuroff S, Chaussy C, Vallancien G et al. Highintensity focused ultrasound and localized prostate cancer: efficacy results from the
European multicentric study. J Endourol 2003; 17: 673-677

2 Gignoux BM, Scoazec JY, Curiel L et al. [High intensity focused ultrasonic destruction of hepatic parenchyma]. Ann Chir 2003; 128 : $18-25$

3 Melodelima D, N'Djin WA, Parmentier $\mathrm{H}$ et al. Thermal ablation by high-intensity-focused ultrasound using a toroid transducer increases the coagulated volume. Results of animal experiments. Ultrasound Med Biol 2009; 35: 425-435

4 N'Djin WA, Melodelima D, Schenone $F$ et al. Assisted hepatic resection using a toroidal HIFU device: an in vivo comparative study in pig. Med Phys 2011; 38: $1769-1778$

5 Wang ZB, Wu J, Fang $L Q$ et al. Preliminary ex vivo feasibility study on targeted cell surgery by high intensity focused ultrasound (HIFU). Ultrasonics 2011; 51: 369-375

\section{Bibliography}

Dol http://dx.doi.org/

10.1055/s-0032-1310061

Endoscopy 2012; 44: E376-E377

(c) Georg Thieme Verlag KG

Stuttgart · New York

ISSN 0013-726X

\section{Corresponding author}

\section{Pioche, MD}

Gastroenterology Department

Pavillon $\mathrm{H}$

Hôpital Edouard Herriot

5 place d'Arsonval

Lyon 69003

France

Fax: +33-472-110147

mathieupioche@free.fr 